\title{
PROFIL ASAM LEMAK MINYAK SA WIT SETELAH PROSES PENGGORENGAN IKAN
}

\author{
Silvana D. Harikedua ${ }^{1}$, Vera T. Harikedua ${ }^{2}$ \\ 1) Staf pengajar pada Program Studi Teknologi Hasil Perikanan FPIK Unsrat Manado \\ ${ }^{2)}$ Staf pengajar pada Program Studi Gizi Poltekkes Kemenkes Manado \\ Email: silvana.harikedua@unsrat.ac.id
}

\begin{abstract}
The fatty acid profile of palm oil is presented in this work. The palm oil (control) was rich in palmitic acid $(39.01 \%)$ and oleic acid $(44.50 \%)$. The results indicated that fish frying process for about 60 minutes was given little differences fatty acid profiles compared to control palm oil. The major fatty acid in the palm oil after frying fish was palmitic acid (41.13\%) and oleic acid (42.62), and developed the existenceof palmitoleic acid $(0.28 \%)$, which is not found in control palm oil.
\end{abstract}

Keywords: fatty acid profiles, palm oil, frying fish.

\section{PENDAHULUAN}

Penggorengan adalah salah satu metode memasak paling tua yang tetap digunakan orang dari dulu sampai sekarang. Kelebihan proses penggorengan dengan proses memasak lainnya terutama disebabkan pada kemunculan citarasa dan tekstur yang unik dalam bahan pangan yang diolah. Selain itu proses penggorengan dapat menurunkan waktu preparasi (penyiapan bahan awal) produk, menerapkan proses thermal bagi bahan makanan sehingga produk menjadi cepat matang sehingga kerusakan pangan sebagai akibat penggorengan biasanya tidak lebih besar dari kerusakan karena proses memasak lainnya.

Minyak sawit adalah minyak yang biasanya digunakan sebagian besar masyarakat Indonesia sebagai medium penggorengan. Minyak sawit tersusun dari unsur-unsur $\mathrm{C}, \mathrm{H}$, dan O. Minyak sawit mengandung asam lemak dalam jumlah cukup banyak dan asam lemak tersebut berikatan dengan gliserol membentuk trigliserida. Menurut Morad et al. (2006) komponen trigliserida dalam minyak sawit kasar mencapai 95 persen. Rantai asam lemak yang terdapat pada trigliserida minyak sawit dapat bervariasi jumlah atom karbon dan strukturnya (adanya ikatan rangkap seperti ketidakjenuhan). Variasi struktur dan jumlah karbon pada rantai asam lemak menggambarkan sifat fisik dan kimia minyak sawit (Basiron 2005). Menurut Winarno (1999) trigliserida minyak sawit seperti trigliserida alami pada umumnya, mengandung asam lemak jenuh pada posisi 1 dan/atau 3 serta asam lemak tidak jenuh pada posisi 2 , namun ada juga beberapa trigliserida yang ketiga asam lemak penyusunnya asam lemak jenuh.

Proses penggorengan dapat
menyebabkan terjadinya perubahan-perubahan sifat fisik dan kimia minyak sebagai medium penggorengan. Komposisi asam-asam lemak dalam minyak sawit diduga dapat mengalami perubahan karena proses penggorengan. Penelitian ini dilakukan untuk mempelajari profil asam lemak minyak sawit dengan membandingkan minyak sawit murni (kontrol) dengan minyak sawit yang sudah digunakan untuk menggoreng ikan selama 60 menit. Analisa komposisi asam lemak dilakukan dengan prosedur metilasi menggunakan kromatografi gas.

\section{METODE PENELITIAN}

\section{Bahan dan Alat}

Bahan untuk menggoreng adalah Ikan Tongkol (Auxis thazard, L). Minyak yang digunakan untuk menggoreng adalah minyak sawit merk Bimoli. Bahan kimia yang digunakan Standar internal C17 asam margaratl; Heksana; NaOH-metanol; $\mathrm{BF}_{3}$ metanol kompleks; $\mathrm{NaCl}$ jenuh; Aliran gas Nitrogen $\left(\mathrm{N}_{2}\right) ; \mathrm{Na}_{2} \mathrm{SO}_{4}$ anhydrous. Alat yang digunakan alat penggorengan dan perlengkapan lainnya; Termometer; Timbangan analitik; Erlenmeyer; Tabung Reaksi; Pipet; Gas Chromatography; Vortex.

\section{Persiapan Sampel Ikan}

Ikan sebanyak $2 \mathrm{~kg}$ (2 ekor ikan ukuran panjang $20 \mathrm{~cm}$ dengan berat @ $1000 \mathrm{~g}$ 
dibersihkan dari isi perut dan sisik-sisiknya, dicuci bersih. Ikan dipotong kecil-kecil dari kepala sampai ekor dan dicuci kembali sampai bersih dari kotoran dan darah, ditiriskan kemudian digoreng sampai matang pada suhu $90^{\circ} \mathrm{C}$ dilakukan pada semua sampel. Setiap kali penggorengan dimasukan 3 potong ikan dan dihitung waktunya. Setelah 60 menit penggorengan diambil sampel minyak dimasukkan ke dalam erlenmeyer, kemudian diberikan label. Sampel minyak didinginkan kemudian dilakukan proses metilasi menggunakan GC.

\section{Prosedur Metilasi dengan Gas Chromatography}

$100 \mathrm{mg}$ minyak sawit ditambahkan standard internal $\mathrm{C} 17$ asam margarat, ditambahkan $\mathrm{NaOH}$-metanol $1.5 \mathrm{~mL}$, dan dihembus dengan gas $\mathrm{N}_{2}$. Selanjutnya sampel dipanaskan 5 menit, didinginkan, ditambahkan larutan $\mathrm{BF}_{3}$ dalam methanol, dihembuskan kembali dengan gas $\mathrm{N}_{2}$, dipanaskan selama 25 menit, didinginkan, ditambahkan heksana 1,5 $\mathrm{mL}$ dan $\mathrm{NaCl}$ jenuh, diambil lapisannya yang terpisah, ditambahkan $\mathrm{Na}_{2} \mathrm{SO}_{4}$ anhydrous, dimasukkan ke dalam vial dan sampel siap dimasukkan ke dalam GC.

\section{HASIL DAN PEMBAHASAN}

Analisis minyak dengan menggunakan GC pada prinsipnya menggunakan gas sebagai pembawa yang memisahkan masing-masing gliserida berdasarkan titik uapnya. Gas pembawa yang umum digunakan adalah $\mathrm{N}_{2}, \mathrm{He}$ dan $\mathrm{H}_{2}$. Senyawa yang lebih mudah menguap akan keluar terlebih dahulu. Karena titik uap gliserida umumnya tinggi $\left(>300^{\circ} \mathrm{C}\right)$, maka sampel perlu diderivatisasikan menjadi bentuk senyawa yang memiliki titik uap lebih rendah sehingga lebih mudah menguap.

Menurut Din (2005) disitir Haryati (2007) derivatisasi minyak dapat dilakukan melalui proses silisasi menggunakan $\mathrm{N}$-methyl$\mathrm{N}$-trimethysilyltrifluoroacetamida (MSTFA), puncak yang keluar pada kromatogram GC menunjukkan puncak dari jumlah karbon masing-masing gliserida. Proses metilasi yang dilakukan pada minyak sawit (kontrol) tanpa diberi perlakuan dan minyak sawit yang telah dipakai untuk menggoreng ikan selama 60 menit dapat memberikan perbandingan akan komposisi asam-asam lemak bebas yang terkandung didalamnya.

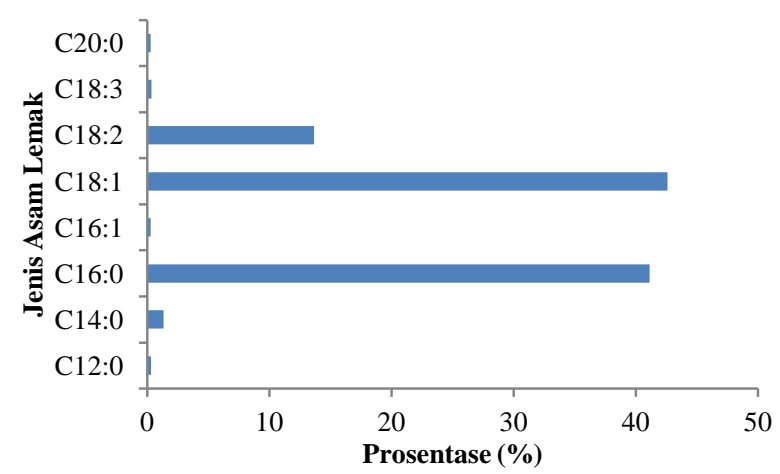

Gambar 1. Profil Asam Lemak Minyak Sawit Kontrol.

Komponen asam lemak yang dominan untuk minyak sawit (Gambar 1) adalah jenis asam palmitat (C16:0) dan asam oleat (C18:1). Komposisi asam lemak pada minyak sawit yang telah dipakai menggoreng selama 60 menit untuk ikan (Gambar 2) juga menunjukkan komposisi asam lemak yang serupa dengan minyak sawit kontrol, akan tetapi dengan tingkat konsentrasi berbeda. Khusus untuk minyak sawit yang digunakan untuk menggoreng ikan terdeteksi juga asam palmitoleat (C16:1) hal ini diasumsikan muncul akibat hasil penguraian asam-asam lemak tidak jenuh rantai panjang seperti DHA (asam dokosaheksaenoat) dan EPA (eikosapentaenoat) yang banyak terdapat pada ikan tongkol.

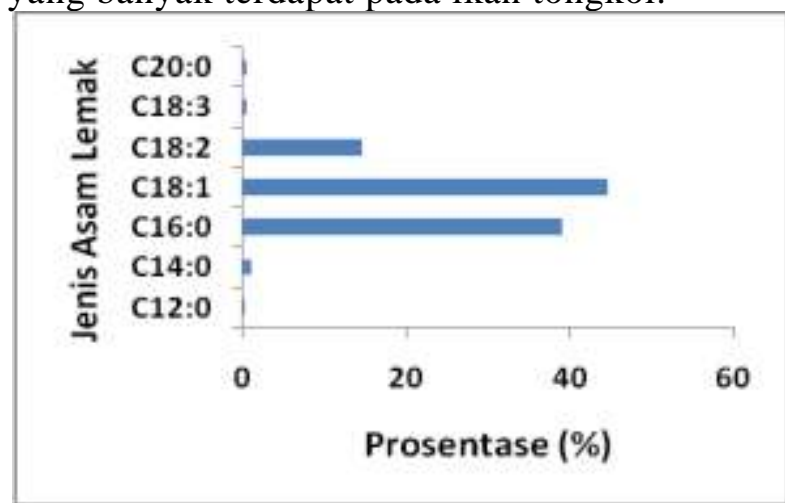

Gambar 2. Profil Asam Lemak Minyak Sawit Setelah Penggorengan Ikan Selama 60 Menit.

Jika dibandingkan maka dapat dilihat bahwa pada minyak sawit yang dipakai untuk menggoreng ikan konsentrasi asam palmitat cenderung lebih rendah daripada minyak sawit control, sedangkan konsentrasi asam oleatnya cenderung lebih tinggi daripada minyak sawit kontrol. Hal ini bisa terjadi karena pada proses penggorengan terjadi hubungan timbal balik antara medium penggorengan dan bahan pangan 
yang digoreng. Prosesnya diawali dengan adanya proses penyerapan minyak oleh bahan pangan dan proses kontaminan dari bahan pangan terhadap minyak. Hal ini tentu saja mempengaruhi komposisi dan konsentrasi asam lemak bebas pada minyak. Ikan tongkol memiliki kadar air yang tinggi, air dari bahan pangan yang bercampur dengan minyak dapat memicu terjadinya reaksi-reaksi hidrolitik pada minyak, proses ini pada gilirannya dapat mempengaruhi kualitas minyak yang dipakai untuk menggoreng.

\section{KESIMPULAN}

Melalui penelitian ini dapat disimpulkan beberapa hal, yaitu:

1. Asam lemak bebas yang dominan terdapat pada minyak kelapa sawit adalah asam palmitat dan asam oleat.

2. Asam palmitoleat terdeteksi pada minyak sawit yang telah digunakan untuk menggoreng ikan selama 60 menit, dan tidak terdeteksi pada minyak sawit kontrol.

3. Proses penggorengan memunculkan komposisi dan konsentrasi asam lemak minyak sawit yang berbeda dengan minyak sawit kontrol.

\section{DAFTAR PUSTAKA}

Basiron Y. 2005. Palm Oil. Di dalam: Shahidi, F, editor. Bailey's Industrial Oil and Fat Products. Ed ke-6. Canada : A John Wiley \& Sons, Inc. Vol 2. hlm $333-420$

Haryati T. 2007. Analisis Komponen Gliserida untuk Mengidentifikasi Jenis Minyak/Lemak. Food Review Vol 2 No. 3 Maret 2007.

Morad NA, MMKA Aziz, Rohani. 2006. Process Design in Degumming and Bleaching of Palm Oil. Centre of Lipids Engineering and Apllied Research (CLEAR). Malaysia: Universiti Teknologi Malaysia.

Winarno FG. 1999. Minyak Goreng dalam Menu Masyarakat. Bogor: Pusat Pengembangan Teknologi Pangan Institut Pertanian Bogor. 